\title{
Hazard, Vulnerability and Risk on the Brahmaputra Basin: A Case Study of River Bank Erosion
}

\author{
Nayan Sharma ${ }^{1} *$ Fiifi Amoako Johnson ${ }^{2}$ Craig W. Hutton ${ }^{3}$ and Mike Clark ${ }^{3}$ \\ ${ }^{I}$ Water Resources Development \& Management, Indian Institute of Technology Roorkee, Roorkee - 247 667, India \\ ${ }^{2}$ School of Social Sciences, University of Southampton, UK \\ ${ }^{3}$ GeoData Institute, University of Southampton, Southampton, UK
}

\begin{abstract}
The authors present an assessment of risk from river bank erosion in the Brahmaputra river basin. The concept of risk is conceptualised in the context of socio-economic vulnerability, and the potential for exposure to hazard. By addressing both the physical hazard and the variations across the socio-economic surface the approach presented attempts to spatially combine these parameters to provide a risk surface for use by policy makers and decision makers at a number of administrative levels. The concept of vulnerability and risk as a description of the status of a society with respect to an imposed hazard such as flooding or the associated bank erosion exacerbated by climate change is deep rooted in a very broad research effort and its associated publications. In part, this reflects the complex evolution of the underlying notion of hazard - which itself shows the concurrent evolution of a series of strands each representing one disciplinary tradition. The concept of vulnerability has been very widely treated in the literature, and for present purposes an acceptable approach to vulnerability may be to start with an influential (but still controversial) established model by IPCC (2001) who have developed working definition - and then explore its ramifications in order to develop a set of working definitions and operational indicators for the project. This provides a pragmatic route towards a realistic target. It also offers a possible buffer against the common experience that the more sophisticated indices of vulnerability are strongly sensitive to contingent local/historical circumstances. This approach is explored within this chapter. The hazard posed by unabated bank erosion has been analysed with the help of satellite imagery based data and through adoption of Plan Form Index along with its threshold values developed for the Brahmaputra. The land loss to erosion is depicting a significantly rising trend which has contributed to the impoverishment of the riverine population. The attendant uncertainties of climate change on hydrological and hydraulic river behaviour may exacerbate the channel instability of the Brahmaputra.
\end{abstract}

Keywords: Bank erosion, braid index, Brahmaputra, climate change \& vulnerability mapping.

\section{INTRODUCTION}

The Brahmaputra is a trans-boundary river with its origin in south-western Tibet going through the Himalayas in the great gorges and into Arunachal Pradesh. It flows southwest through the Assam State of India and south through Bangladesh into the sea. This study focuses on the Assam Basin of the Brahmaputra River which stretches $720 \mathrm{~km}$ long and 90 $\mathrm{km}$ wide [1] and is home to more than 26 million inhabitants [2]. The channel of the river occupies about one-tenth of the valley, with over $40 \%$ of its area under cultivation. The basin is an example of an extremely heterogeneous watershed with complex topography, high spatial variability in land cover. Additionally, the climate is complex within the catchment because of the altitudinal range, the geographical location and the influence of the South Asian monsoon systems.

The Basin has been subjected to extensive bank erosion hazard with numerous social and economic disasters, particularly during floods in the monsoon season (June through September) for decades. Glacier retreat and changes in pre

*Address correspondence to this author at the Water Resources Development \& Management, Indian Institute of Technology Roorkee, Roorkee 247 667, India; Tel: 0091-1332-285781, 271073, 285251; Fax: 00911332-285781, 271073, 273560;

E-mail: nayanfwt@gmail.com cipitation patterns has increased flash flood and flood flows which in its wake create greater inundation and river bank erosion in the basin [3], a process which is set to continue within the context of all the SRES scenarios. There is also an extremely high volume of sediment that is accumulated within the Brahmaputra River as a result of its several tributaries and the seismically active hill ranges surrounding the Basin, intensifying the rate of bank erosion $[4,5]$. Between 1912 and $1996,868 \mathrm{~km}^{2}$ of land was lost to bank erosion; averaging $10.3 \mathrm{~km}^{2}$ of area lost per year [3]. The average bank-line shift of the north bank towards the north is estimated at $227.5 \mathrm{~m} / \mathrm{year}$ on average, $331.6 \mathrm{~m} / \mathrm{year}$ from the north bank towards the south, $137.2 \mathrm{~m} / \mathrm{year}$ from the south bank towards the south and $225 \mathrm{~m} / \mathrm{year}$ from the south bank towards the north [3].

The extensive bank erosion in the basin has led to numerous social and economic consequences - loss of agricultural land (loss of livelihood), loss of housing and other essential infrastructure, displacement and involuntary migration promoting native-migrant contest over limited resources, ethnic tensions, distrust and political instability and civil strife in the basin [6]. High human intrusion (massive encroachments and deforestation) on the natural landscape of the basin [7], resulting in heavy siltation in recent times has also made worse the extent of bank erosion in the basin. 
Within this context this paper aims to define a past trend in bank erosion as the basis for expectation of future potential hazard and associate this finding with the occurrence of vulnerability to this hazard. This work does not as yet extend to formal model-based forecast of either bank erosion or socioeconomic vulnerability to bank erosion. However trend analysis and current occurrence, it is suggested, will provide a substantive input to the decision making process for near future policy and planning. To this end this work aims to:

1. Specify a model based approach and associated metrics required to characterise the impacts and potential of bank erosion

2. Understand how bank erosion impacts the socioeconomic well-being of residents in the study area of the basin

3. Produce an indicative risk map which combines hazard (bank erosion) and vulnerability to produce a first order "at risk" assessment for current and near future bank erosion

In this study we use an adapted IPCC [8] approach to risk conceptualisation which characterises risk as a function of vulnerability to the hazard and the nature of the hazard.

Risk $=\mathrm{f}($ Vulnerability, Hazard $)$

In cases where the hazard is bank erosion, which has an exposure (spatial distribution intersecting with asset or population) and magnitude, vulnerability is composed of Sensitivity and Adaptive Capacity. Sensitivity here refers to the degree to which a system is affected, adversely or beneficially, by bank erosion and adaptive capacity to refer to the ability of a system to adjust to the effects of bank erosion and moderate potential damages or cope with the consequences. We refer to the different components of sensitivity and adaptive capacity as domains. These concepts are discussed in details in subsequent sections. Profiling the multi-dimensions of socioeconomic vulnerability will inform policy makers the appropriate interventions to initiate in a given area. The methodology proposed in this paper has a great potential to be adopted by other researchers in different settings.

The map presented in Fig. (2) is a summary of at risk findings generated through the study laid out below pertaining to the Brahmaputra Basin in Assam. It constitutes the singularly most useful output of the work and provides a context for future research in this area as well as giving a broad trend in risk for the development of relevant policy.

The key interpretation is a simple one, namely that where highly vulnerable populations (red) are coincident with high and medium level potential hazard exposure (derived by trend) then these areas are deemed at risk. Reaches 5, 10 \& 11 on both banks would appear to be a bank erosion priority with a particular focus on the South bank of reach number 5 . From the authors' field experience, this is a known wetland area which is undergoing substantial erosion and is home to a population with a high proportion living in difficult social circumstances.

Such an approach as that shown here would of course need to be validated prior to the development of policy (a process under research development by the authors) but does allow for a first order delineation of resource allocation for further exploration.

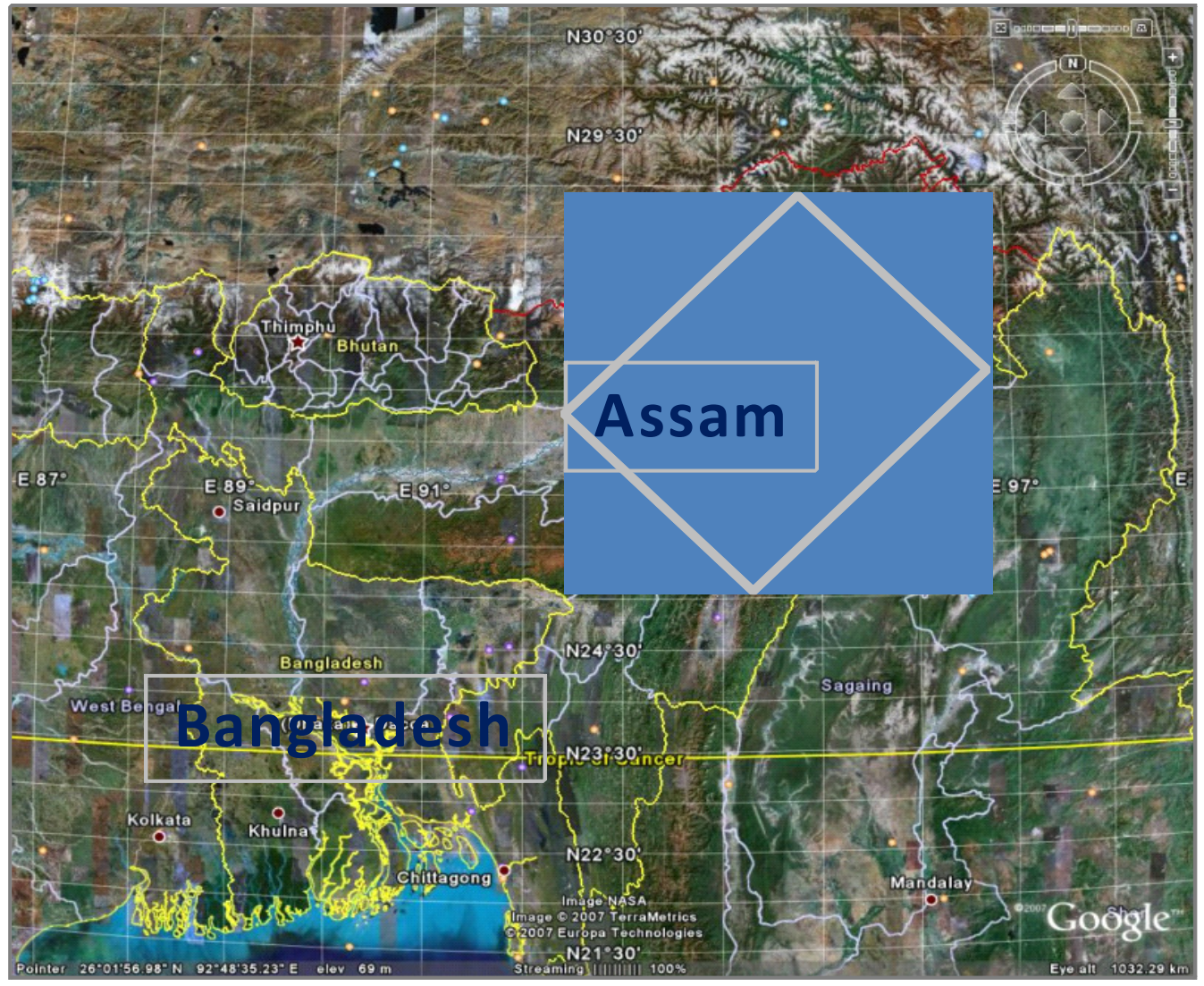

Fig. (1). Assam, N.E. India, study site is marked by the grey square. 


\section{ANALYSIS OF STREAM BANK EROSION PROC- ESSES IN BRAHMAPUTRA}

The Brahmaputra flows through the Indian state of Arunachal Pradesh for $278 \mathrm{~km}$, mostly across the Himalayas, where it is called Dihang or Siang. The Dihang debouches onto the plains at Pasighat (elevation $155 \mathrm{~m}$ ). Near Kobo in Assam, $52 \mathrm{~km}$ downstream from Pasighat, the Dihang is joined by two large rivers - the Lohit and the Dibang, and from hereafter the river is known as the Brahmaputra. The Brahmaputra flows for about $670 \mathrm{~km}$ through the province of Assam, where it receives 103 tributaries - 65 on the right (north) bank and 38 on the left (south) bank [9] The mighty Brahmaputra along with the well-knit network of its tributaries controls the geomorphic regime of the entire region, especially in the Brahmaputra valley.

Significant areas of prime inhabited land are lost every year to river erosion in the Brahmaputra basin thereby the affected people become impoverished due to sudden loss of home and hearth. Furthermore, unrelenting bank erosion process has caused channel widening and braiding which created navigation bottleneck zones in the Brahmaputra due to inadequate draught during non-monsoon. For efficient management of unabated bank erosion problem spanning over hundreds of kilometre length along the Brahmaputra, there is an imperative need for a rational braiding indicator that can aid monitoring of intricate fluvial landform changes, help prioritization of erosion zones, and facilitate maintenance all-weather fairway.

In the above backdrop, the intense variability and complexity of the fluvio-morphological features of the Brah- maputra River are captured in sufficient details to elicit meaningful abstraction of channel processes and morphology.

The intense braided rivers, like the Brahmaputra are hydraulically less efficient, and the formation of braid bars plays an important role in the dissipation of the energy due to friction. The existing braid indicators do not appropriately reflect the pertinent channel variables in their formulations.

Sharma (2004) developed Plan Form Index (PFI), Flow Geometry Index (FGI), and Cross-Slope ratio for identifying the degree of braiding of highly braided river. The PFI, FGI and Cross- Slope formulae have been given below:

Plan Form Index $=\frac{\frac{T}{B} \times 100}{N}$

Flow Geometry Index $=\left[\frac{\sum d_{i} x_{i}}{W x D}\right] \quad x N$

Cross-Slope $=\frac{\frac{B_{L}}{2}}{(\text { Bank level }- \text { Av. bed level })}$

where, $\mathrm{T}=$ flow top width; $\mathrm{B}=$ overall width of the channel; $\mathrm{B}_{\mathrm{L}}=$ Transect length across river width; $\mathrm{N}=$ number of braided channel; $d_{i}$ and $x_{i}$ are depth and top lateral distance of submerged sub-channel; and $\mathrm{D}=$ hydraulic mean depth.

Plan Form Index (PFI) in Equation 10 (Definition sketch as shown in Fig. 3) reflects the fluvial landform disposition with respect to a given water level and its lower value is in-

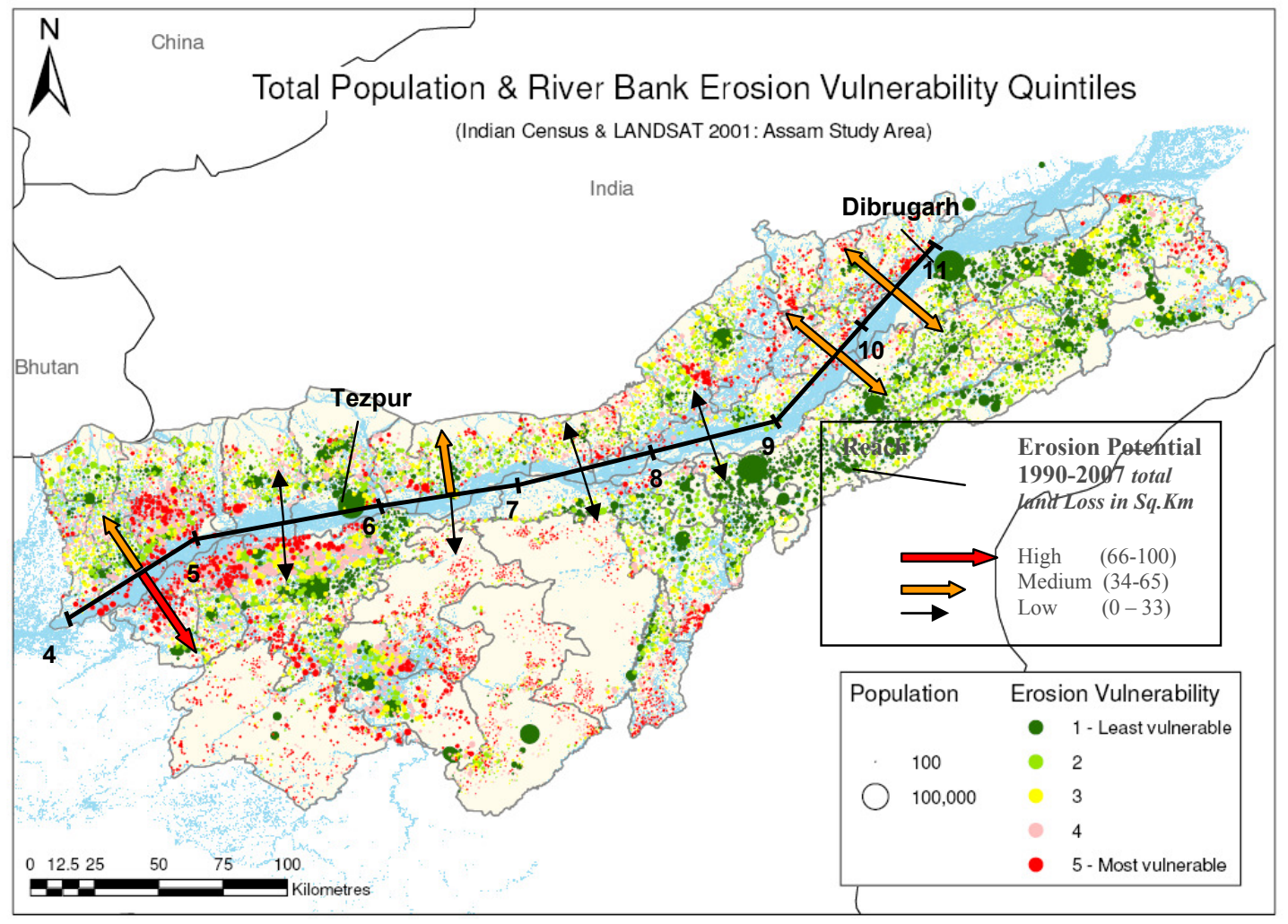

Fig. (2). Risk map showing trends in river bank erosion on the North and South bank of the study area superimposed upon community level assessment of socio-economic vulnerability to bank erosion. Full explanation of the derivation of this data is found in the main body of the text of this paper. 


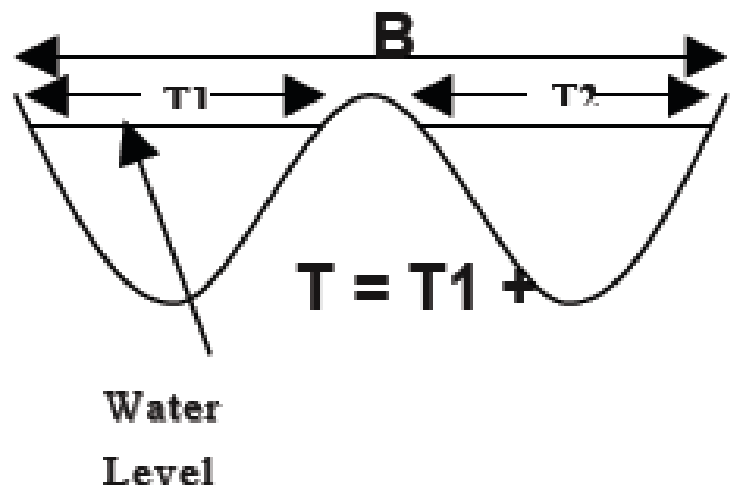

Fig. (3). Definition sketch of PFI.

dicative of higher degree of braiding. For providing a broad range of classification of the braiding phenomenon, the following threshold values for PFI are proposed by Sharma (2004) by considering about 10 kilometres reach length of the Brahmaputra river in Assam state of India.

$\begin{array}{ll}\text { Highly Braided: } & \text { PFI }<4 \\ \text { Moderately Braided: } & 19>\text { PFI }>4 \\ \text { Low Braided: } & \text { PFI }>19\end{array}$

In this study, it is endeavoured to assess the channel morphological changes actuated by stream bank erosion process. The newer braiding indicator PFI for Brahmaputra River formulated by [10] has been adopted in the study to analyze the braiding behaviour. Attempt has been made to assess the temporal and spatial variation of braiding intensities along the whole stretch of Brahmaputra in Assam plains of Indian Territory based on the remote sensing image analyses, which is the forcing function of erosion and thereby causing severe yearly land loss.

\subsection{Brahmaputra Study Area and Extraction of Channel Forms}

Digital satellite images of IRS LISS-III sensor, consisting of scenes for the years 1990, 1997 and 2007-08 are used for the present study. In order to bring all the images under one geometric co-ordinate system, these are geo-referenced with respect to Survey of India (1:50,000 scale) topo-sheets using second order polynomial. IRS-P6 LISS images of 1990, 1997 and 2008 years are geometrically rectified with reference to the LANDSAT images of the same area. The UTM projection and WGS 84 datum has been taken for georeferencing. Rectification of the images was done with a residual RMS (root mean square error) of less than 1 .

The river length under study has been divided into 12 reaches. Each reach comprised of 10 cross sections. The bank line of the Brahmaputra River is demarcated from each set of imageries and the channel patterns are digitized using Arc GIS software. The locations of cross sections are shown in Fig. (5). The data used in the analysis have been presented in Table 1. ERDAS IMAGINE 8.6 image processing software has been used to perform the image processing work. Then satellite images of the other years were co-registered using image-to-image registration technique.

In the above table, the LISS-I sensor of IRS IA satellite has a spatial resolution of 75 metres, while LISS-III sensor of IRS 1C \& D has 23.5 metres resolution. For a plan form study of a large alluvial stream like Brahmaputra having river width as much wide as over 20 kilometres, the above spatial resolution can be considered as adequate.

For convenience in computing, the study area of around $622.73 \mathrm{~km}$ from Dhubri to Kobo beyond Dibrugarh in Upper Assam is considered.

\subsection{Methodology}

Appropriate GIS applications are done to precisely extract bank line information. Segment wise satellite-derived plan-form maps have been developed for the discrete years i.e. 1990, 1997 and 2007-08.

\section{Data Geo Referencing and Image Processing}

One set of Survey of India topo-sheets (1965) and digital satellite images of IRS LISS-I and LISS-III sensors, comprising scenes for the years 1990, 1997 and 2007-08 are used for the present study. In order to assess the rate of erosion, maps and imagery are registered and geo-referenced with respect to Survey of India (1:50,000 scale) topo-sheets using second order polynomial. Using ERDAS imagine software, the satellite data have been geo-referenced with respect to 1:50,000 Survey of India topo-sheets.

The geo-referencing was done by the hardcopy map on digitizing table using second order equation with root mean square error less than 1.0 and nearest neighbourhood resampling technique to create a geo-referenced image of pixel size $23.5 \mathrm{~m} \times 23.5 \mathrm{~m}$. Subsequently other images were also registered with the geo-referenced image using image-toimage registration technique. The registered images for different dates pertaining to study area were used for further analysis.

\section{Delineation of River Bank Line}

For convenience, the main river has been divided into 120 strips, and reference cross sections were drawn at the boundary of each strip. Each ten cross sections are grouped as a reach with numbering from downstream to upstream of the river (of equal base length (Fig. 4; Table 2). Base line of

Table 1. Characteristics of the Remote Sensing Data Used

\begin{tabular}{|l|c|c|c|l|}
\hline \multicolumn{1}{|c|}{ Satellite /Sensor } & Path/Row & Acquisition Period & Spatial Resolution & \multicolumn{1}{|c|}{ Spectral Bands and Channels } \\
\hline \hline IRS IA/LISS-I, IRS 1C and D/ LISS-III (Standard Product) & $112 / 52$ & $1990,1997,2007-08$ & $75 \mathrm{~m}, 23.5 \mathrm{~m}$ & $\begin{array}{l}\text { Visible band-(Green channel) } \\
(0.52-0.59 \mu \mathrm{m})\end{array}$ \\
\hline IRS IA/LISS-I, IRS 1C and D/ LISS-III (Standard Product) & $112 / 53$ & $1990,1997,2007-08$ & $75 \mathrm{~m}, 23.5 \mathrm{~m}$ & $\begin{array}{l}\text { Visible band-Red channel } \\
(0.62-0.68 \mu \mathrm{m}) \text { Near infrared } \\
(\mathrm{NIR})(0.77-0.86 \mu \mathrm{m})\end{array}$ \\
& & & & \\
\hline
\end{tabular}




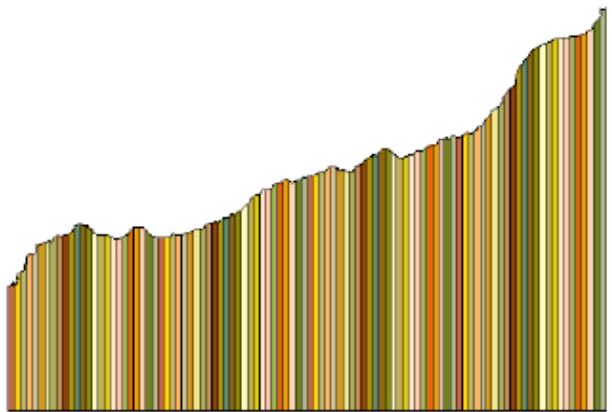

Base line

Fig. (4). 120 strips of left bank.

Table 2. Identification of Reaches in Respect of the Location in the Vicinity

\begin{tabular}{|c|c|}
\hline Reach Number & Locations in Vicinity \\
\hline \hline 1 & Dhubri \\
\hline 2 & Goalpara \\
\hline 3 & Palasbari \\
\hline 4 & Guwahati \\
\hline 5 & Morigaon (Near Mangaldai) \\
\hline 6 & Morigaon (Near Dhing) \\
\hline 7 & Tezpur \\
\hline 8 & U/s of Tezpur (Near Gohpur) \\
\hline 9 & Majuli (Near Bessamora) \\
\hline 10 & U/s of Majuli (Near Sibsagar) \\
\hline 11 & Dibrugarh \\
\hline 12 & U/s of Dibrugarh \\
\hline
\end{tabular}

Latitude $25.966^{\circ}$ and Longitude $90^{\circ} \mathrm{E}$ has been taken as permanent reference line. The derived data for each cross section from satellite images of years 1990, 1997, 2008 have been analyzed and the bank lines are also digitized for all the years. The length of arcs of both the left and right banks for all the above years are found out using GIS software. The years 1990, 1997 and 2008 have been taken for analyzing erosion and deposition along the river left bank as well as right bank. The above scheme of making 120 strips for the left bank line is broadly indicated in the strip layout plan shown in Fig. (4) wherein the base line is adopted as latitude 25.966 degree.

Intermediate channel widths, and total widths of channel at each predefined cross sections are measured using GIS software tools for computing Plan Form Indices for each cross sections for further analysis.

Erosion in north and south banks of the river area during the study period (that is 1990-2007-08 and 1997-2007-08) is estimated by GIS software tools through delineating the river bank lines and drawing polygons within bank line variations within the study period

The computed Plan Form Index for each reference crosssection totalling 120 in numbers across the study reaches are plotted against reach cross-section number in Fig. (6) for three discrete years. From the plot, it can be readily inferred that from 1990 to 2007-08, the PFI values by and large decrease significantly indicating the increase in braiding intensities in majority of cross sections considering the fixed threshold values of PFI given for measuring braiding intensity mentioned in Sec. 2 [10] of this paper.

It strongly suggests that irrespective of the time, the aforementioned four discrete reaches show little changes in braiding intensity and pattern. It confirms the existence of the aforesaid four geological control points which hold the river, and in between there are intermittent fanning out of the river with time. Other than these river control points, more braiding is expected where bank line configurations and characteristics are conducive for braiding to occur in other reaches.

As discussed, the graphical plots of Plan Form Index for the Brahmaputra River shows increasing trend thereby registering an increasing level of braiding, as can be seen from the threshold limits. Plots for all reference cross sections for the years 1990, 1997 and 2007-08 between PFI's and cross section numbers shows the increasing trend of braiding with

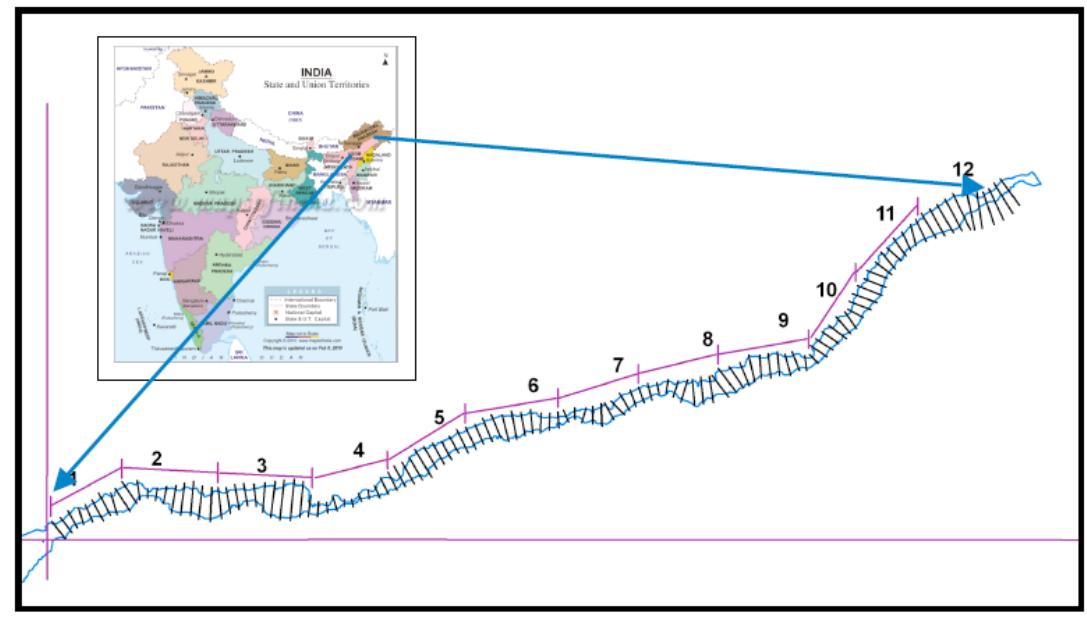

Fig. (5). Reach map of the Brahmaputra study area defining location of river sections. Please see Figs. (1) \& (2) for locations of reaches. 


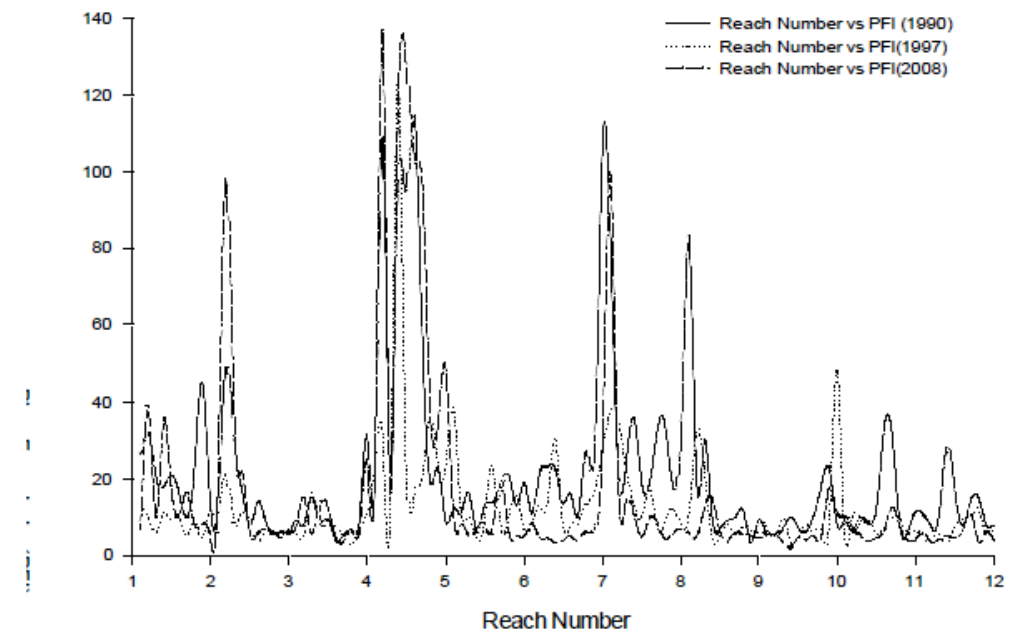

Fig. (6). Cross-section wise Plan Form Index (PFI) values in different reaches of the Brahmaputra River in years 1990, 1997 and $2007-08$.

time. These plots clearly demonstrate the rationality of using the Plan Form Index as a measure of braiding and closely conform to the actual physical situation of the occurrence of braiding vividly depicted in satellite images. In light of the threshold values of Plan Form Index, it can be readily inferred from graphical plots showing maximum, minimum and mean values of PFIs of cross sections that have heavy with moderate and low braiding characteristics resulting in a very complex channel hydrodynamics.

Using GIS software, vector layers of the bank line and river flow domain have been worked upon and results have been presented in Table $\mathbf{3}$, which accounts for the reach wise erosion area for periods 1990-2007-08 and 1997- 2007-08. Erosion lengths within the reaches have been identified based on the exhibited bank line shifts in the duration of study area. Similarly erosion area is estimated approximately through area estimation using GIS software tools for polygon areas with the shifting bank-lines in study period.

Fig. (7) depicts the area eroded in left and right banks of the study reach number 1 to 11 of Brahmaputra. In reach -2 near Goalpara right bank shows considerable shifting with narrowing down to incised channel at Pandu near Guwahati

Table 3. Satellite Based Estimation and Comparison of Area Eroded in Brahmaputra During the Period 1990 to $2007-08$ and 1997 to 2007-08

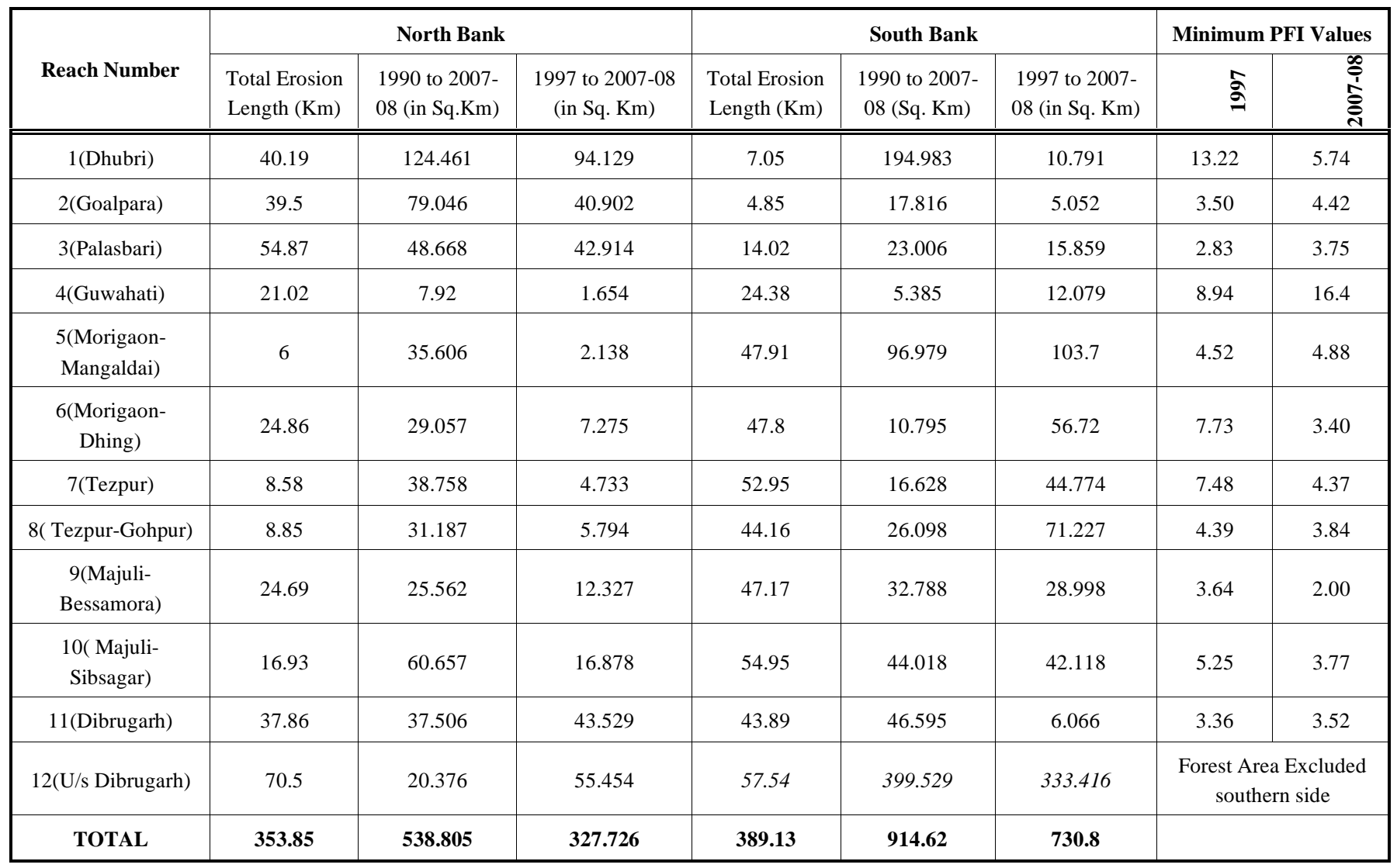



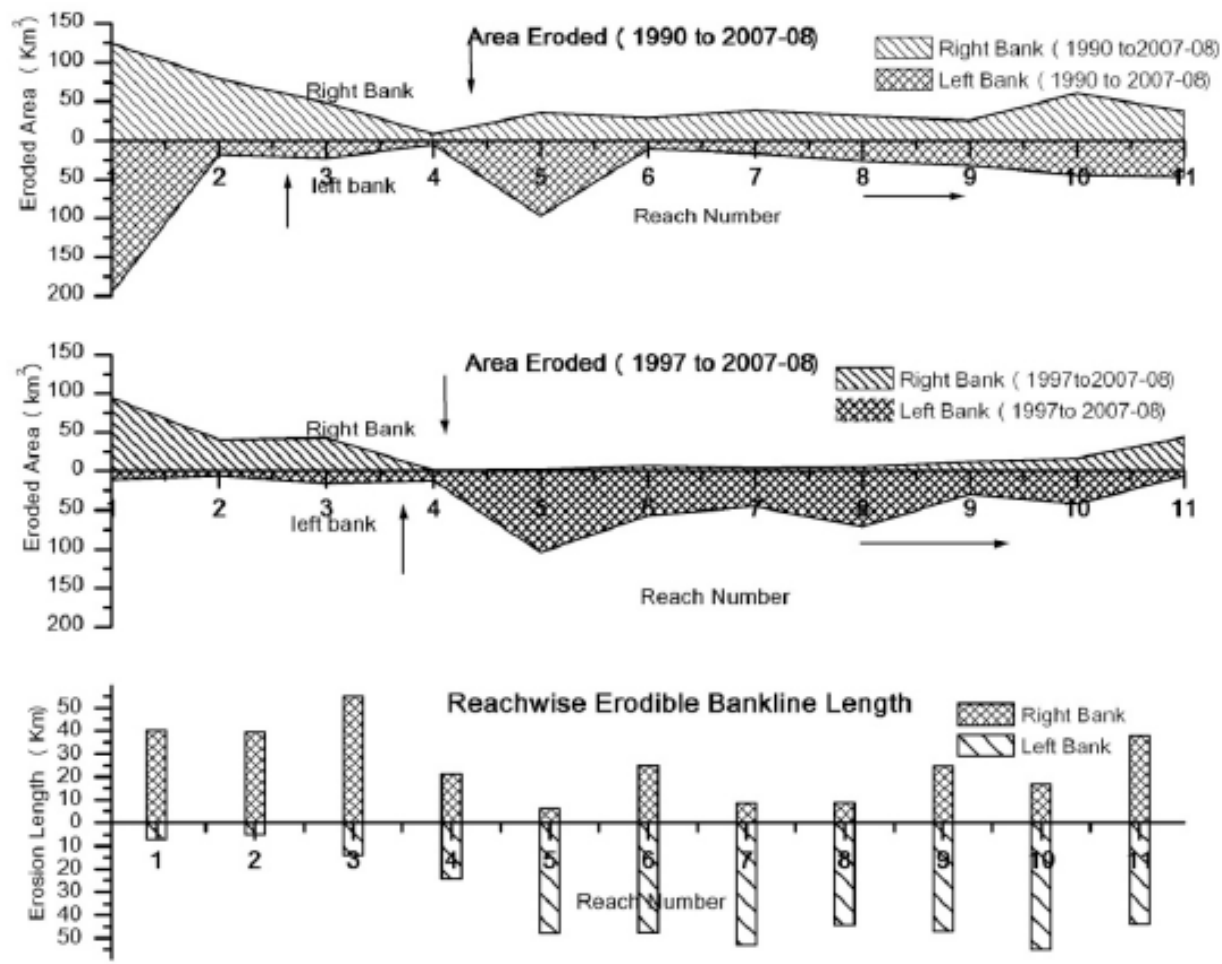

Fig. (7). Reach-wise eroded area during 1990 to 2008 and 1997 to 2008.

in reach-4. Table 3 shows the land loss due to erosion and braiding in left as well as right bank of the Brahmaputra in the period 1997-2007-08 and 1990-2007-08 respectively. Table 3 indicates very high eroded area in the left bank- line of reach-12 during the study period which is the implication of serious avulsion phenomenon during this period in the upstream of Dibrugarh where the Brahmaputra River practically changed its dominant path warranting in-depth analysis separately.

Plot of reach-wise land loss and erosion prone bank length (Fig. 7) indicates that downstream of Guwahati, river tends to move towards right side whereas in upstream side it tends towards south side keeping the control point at Guwahati invariant. Similar pattern repeats at other control points also. It warrants in-depth study of interaction of geo-tectonic activities conjunctively with fluvial regime in the region to understand the complex physical processes completely for suggesting more practical result oriented river management interventions. The ongoing erosion activities and land loss in different reaches in the period 1990-2007-08 are extracted by remote sensing data analysis.

The satellite image based estimation of area eroded in Brahmaputra during periods 1990 to 2007-08 and 1997 to 2007-08 is presented in tabular form (Table 3), which shows the eroding tendency along the river banks of Brahmaputra in the entire study area. For the period of 17 years, the total land loss per year excluding forest area is found out to be $62 \mathrm{~km}^{2} /$ year. For more recent period of 1997 to $2007-08$ the total land loss per year (excluding avulsion) is found out to be $72.5 \mathrm{~km}^{2} /$ year which is registering sharp increase in land lost due to river erosion in recent years. This calls for a robust and efficient river management action plan to arrest huge valuable land losses to erosion.
Moreover, vulnerability of the stream bank erosion is significant as evident from Table 3. Almost $750 \mathrm{~km}$ of bank line in both side of the river has potential erosion tendency. The plot of potential erodible bank length versus Reach Number (Fig. 7) also shows that downstream of Guwahati (Reach Number 4), erosion is considerably high in north bank line whereas in the upstream of Guwahati erosion tendency is considerably high in south bank-line, indicating that river geological control point at Guwahati in respect to other control points has significant causative impact on the morphological behaviour of River Brahmaputra as a whole in Assam flood plains. It urgently warrants attention for undertaking the integrated river management planning of Brahmaputra on holistic approach.

One of the notable outcomes of the present investigation is a pointer to the intimate relationship between land losses due to bank erosion with corresponding increase in braiding intensity. Braiding intensity is exacerbated by high energy environment of flow domain with heavy sediment inputs from the associated catchments. There arises the need for indepth analysis of catchment and its treatment as well as a disaster impact assessment programme, which can be better understood through the latest technology. It is of utmost importance to have a consensus on evolving a durable long term solution. The prime conclusions are summarized below.

- The research on bank erosion of the Brahmaputra has succinctly demonstrated the rational use of the newer braiding indicator namely Plan Form Index (PFI) developed by Sharma [10] with high resolution remote sensing satellite data application to analyze and monitor the complex braiding behavior of a large braided river like the Brahmaputra. The present study also shows that Plan Form Index (PFI) suitably fulfills the need for a rational braiding indicator which should be 
easy to compute making use of synoptic coverage provided by satellite imageries.

- The present study made using the above methodology brings to the fore that Brahmaputra River has been exhibiting sharp increase in fluvial landform changes with heightened braiding intensity in recent years causing sizeable land losses.

- The study amply suggested that three to four major geological channel control points are present along the Brahmaputra in Assam flood plains which are by and large holding the river around the present alignment. These control points are in the vicinity of Jogighopa near Goalpara, Pandu near Guwahati, Tezpur and Bessemora in Majuli.

- The channel control points are surmised to be the major co-actors, working in unison with other forcing functions causing severe erosion. Heavy braiding has occurred due to high level dissipation of flow energy when the river emerges downstream of control points (rock outcrops) to more vulnerable sandy and lightcohesive plains. The manifestation of the highest river width of about $20 \mathrm{Km}$ near Mukalamua-Palasbari from constricted width of about $1.2 \mathrm{Km}$ near Guwahati is the classic example of the above observation.

\section{DEFINING THE CONCEPT OF VULNERABILITY}

The concept of vulnerability, as a descriptor of the status of a society or community with respect to an imposed hazard or threat, is deep rooted in a very broad research effort. The concept of vulnerability has been very widely treated in the literature, and the recent review by Villagrán [11] and Birkmann [12] draws together some highlights of a range of opinions. In regard to the assessment and reduction of socioeconomic vulnerability to climate hazards, different research and policy communities such as the disaster risk reduction, climate change adaptation, environmental management and poverty reduction community have taken up the discussion [13].

For the purpose of this study, the optimum approach to vulnerability is to start with an influential established model - the IPCC [14] working definition - and then explore its ramifications in order to develop a set of working definitions and operational indicators for the study. Although, this may lack some of the sophistication of the conceptual literature, it provides a pragmatic route towards a realistic target for assessing vulnerability in data scarce regions. The starting point is to consider the core concept embodied in the IPCC's implicit definition of vulnerability as the degree to which a system is susceptible to, or unable to cope with, the adverse effects of climate change [8]. The relation can be expressed as:

Vulnerability $=f$ (Hazard, Sensitivity, Adaptive capacity) (5)

The term coping capacity is often substituted for adaptive capacity, but appears sensu lato to have the same definition. The UK Department for International Development [15] proposed:

Vulnerability $=($ Exposure $\mathrm{x}$ Susceptibility $) /$ Coping Capacity

This is another form of Equation 5, as susceptibility has been substituted for sensitivity, and coping capacity substi- tuted for Adaptive Capacity. For the purpose of this study, adaptive capacity is the preferable term as it relates most effectively to the concept of adaptive management and is more easily generalised to reflect society's ability to grasp opportunities as well as respond to threat. Both Equations 5 and 6 emphasises the role of adaptive/coping capacity, but [16] moves further and identifies actual deficiencies in adaptive capacity as being pivotal:

Risk $=f($ Hazard $\mathrm{x}$ Vulnerability $\mathrm{x}$

Deficiencies in Preparedness)

Equation 5 is clearly the fundamental relationship that drives the vulnerability model, and suggests that vulnerability reflects the sum of the risks (hazards) to which a society or community is exposed, mitigated by its adaptive or coping capacity (its ability to respond effectively to risk) and compensated by the available alternative economic opportunities.

It is very important to note that climate change does not just bring threats; it also brings opportunities - new economic possibilities, improved environment or possibilities for enriching cultural change. If the new opportunities are more advantageous than the existing assets under threat, then it may not be necessary to "protect" the asset or process at risk. New opportunities may compensate for threats and reduce the need for that society to defend the existing livelihood. It is helpful that this relatively simple view of vulnerability is entirely compatible with the general relationship:

Process Risk $(\mathrm{H})=$ Probability $\mathrm{x}$ Magnitude

This is a simple and well-established statement, with a broad-based application and a fair degree of consensus. It is also easy to relate to human impact and response.

RISK $=f($ Hazard $*$ Vulnerability $)$

The concept of risk combines our understanding of the likelihood of a hazardous event occurring, with an assessment of its impact. Hazardous events can either be naturally occurring, such as earthquakes, tropical cyclones or coastal erosion; or they can be man-made, such as water pollution. Moreover, events can be sudden, as in the case of an earthquake; or they can occur over a period of time, as in the case of most environmental hazards. Despite the huge range of possible formulations, Equation [5], as derived from the IPCC, provides a viable initial working definition - but in practice it is difficult to implement locally in data-poor regions because it includes the full range of both bio-physical and socio-economic factors (hazard and adaptive capacity). However, it can be suggested that the Hazard term in Equation [5] in effect serves mainly to scale the variability of vulnerability, spatially and temporally. Thus, for any one particular place and time, it may be possible to simplify the relationship to:

Vulnerability $=f($ Sensitivity, Adaptive Capacity)

In this form, the variability of vulnerability is seen to be driven locally mainly by socio-economic factors. On this assumption, it is suggested that for the purposes of this study, Equation [5] represents the physical/social interrelationship underlying climate hazard induced vulnerability as a whole, while the simpler Equation 10 is appropriate as a basis for integrating the socioeconomic aspects of vulnerability. 


\subsection{Data}

The data for the analysis comes from the 2001 Indian Population and Housing Census and 2001 LANDSAT data. The LANDSAT data include road density, agricultural land use, distance to main settlements and health centres. The road density and agricultural land use data were extracted using a three kilometre buffer around each village/town point. Agricultural land use is expressed as the proportion of land use on the basis of commercial and non-commercial agricultural land. The distance measures (distance to main settlements and health facilities) are Euclidean distances. The data covers 14775 villages/ towns in the Assam Basin of the Upper Brahmaputra River.

\subsection{Methods}

The analysis is conducted in two parts. The first part involves identifying and ranking the domains, identifying the indicators to quantify them and finally creating an index for the domains and also for the level of sensitivity, adaptive capacity and overall vulnerability. The second part of the analysis involves using different scenarios to investigating how government's policy commitments could mitigate the level of vulnerability.

\subsection{Estimating the Level of Socioeconomic Vulnerability: Identification and Ranking of Domains}

The domains of sensitivity and adaptive capacity were identified through literature review, field observations and discussions with the basin's residents, stakeholders and experts working on both the hydrological and socioeconomic aspects of environmental hazards in the region. The process began with a review of literature on the key environmental hazards in the Basin. This was followed up with a field trip to the basin. During the field trip focus groups discussions were held with the basin's residents. The discussions focused on key environmental hazards, the degree to which resources/systems are affected adversely or beneficially and the ability of the basins residents to adjust, moderate potential damages, take advantage of opportunities or cope with the consequences. Field observations of the impacts of climate hazards were also undertaken and documented. From the literature review, focus group discussions and field observations an inventory of domains and indicators was developed.

A stakeholder workshop was convened to discuss findings from the literature, focus group discussions and observations. The workshop was attended by 64 government officials, representatives of non-governmental organisations, academics and the basin's representatives. The inventory of domains and indicators was presented to the stakeholders, experts and the basin's residents. Further discussions were held and where appropriate revisions were made. This was followed by one-on-one discussions with selected stakeholders and experts. In general, there was consensus between the opinions of the basins residents, stakeholders and experts.

A Delphi technique was then employed in ranking the domains according to their importance and severity. A Delphi approach to stakeholder participation involves each participant at the workshop being asked to rank the key domains presented in order of importance. The total score of the do- mains for each individual participating should sum to a total score of 40 , with the most important domain receiving the highest score and the least important receiving the lowest score. The scores were then averaged over the number of participants. The results were presented to participants and further deliberations undertaken to ensure that at least $95 \%$ of the participants agree with the ranking. This approach was chosen as a way of validating the representatives of the scores. The stakeholders, experts and representatives of the basins residents also indicated which domains represent sensitivity and which ones represent adaptive capacity. The domains, their rankings and how they are incorporated in the analysis are discussed in later sections.

\section{Selection of Indicators}

To avoid potential bias in the selection of indicators [17] a participatory process involving the basin's residents, stakeholders and experts was employed. The criteria for selection of indicators was based on what the basin's residents, stakeholders and experts thought appropriate, relevant and robust for quantifying a specific domain. It is worthwhile mentioning that not all indicators identified by local residents, stakeholders and experts were included in the analysis due to data limitations. The indicators selected for the analysis although may not be exhaustive for assessing environmental hazard induced vulnerability; they have been selected to ensure that it is comprehensive and relevant for the practical assessment of vulnerability to environmental hazards in the given location. The indicators may not be replicated exactly for other regions but could be modified to suit.

\section{Construction of Indices}

A multi-dimensional matrix of indicators was selected to represent each domain. All indicators included in the analysis are converted to standardize $Z$-scores to avoid scale dependence. A maximum likelihood factor analysis was then used to derive a single factor score for each domain. The motivation for using maximum likelihood factor analysis is that in most vulnerability analysis indices are based on addition. However, variables used to quantify vulnerability in most cases are highly corrected and therefore adding them up introduces a bias of double counting due to multi-colinearity (Jones and Andrey, 2007). Factors analysis circumvents the problem of multi-colinearity. The factor scores generated were then ranked, scaled to the range $(0,1)$, by $\mathrm{R}$ where $\mathrm{R}=$ $1 / \mathrm{N}$ for the least sensitive/least adaptive community and $\mathrm{R}=$ $\mathrm{N} / \mathrm{N}$ for the most sensitive/most adaptive community; $\mathrm{N}$ being the number of town/villages in the basin.

To ensure comparability between the domain scores, it is appropriate that the domain scores are derived to have identical distributions with similar minimum and maximum values, with emphases on the tail of the distribution. This helps to clearly distinguish most sensitive and least adaptive communities. The exponential transformation has been widely used in this respect. The 'cancellation property' of the exponential transformation ensures that high scores in one domain do not cancel out low scores in others a process highlighted in the Scottish Executive, 2003. This property is highly desirable when combining scores from different domains. The Scottish Executive (2003) proposed the exponential transformation below: 
$d_{k}=-23 * \log \left\{1-R *\left[1-e^{-\lambda / 23}\right]\right\}$

Where $d_{k}$ is the transformed domain score which ranges between 0 and 100 ( $d_{i}$ for sensitivity domains and $d_{j}$ for adaptive capacity domains), -23 is a mathematical constant which gives a $10 \%$ cancellation property, $\log$ is the natural logarithm, $R$ is the ranked scores, $e$ is the exponential transformation and the parameter $\lambda$ controls the degree of progression of the score. In this case $\lambda=100$. This transformation approach is employed for the analysis because it satisfies all the statistical requirements stated earlier [18].

The next stage of the analysis requires combining the scores derived for each domain to create an overall score of sensitivity and also adaptive capacity. This process requires weighting the indices to reflect their severity or importance of their impact to the basin's residents. Determining weights to attach to different indices to generate an overall index could be in most cases an intricate task. There are a number of prepositions in the literature - theoretical, empirical, policy driven, consensus or purely arbitrary. To ensure that the weights applied to the scores in this study reflect the severity of their impact or importance to the basin's residents, the Delphi scores were used to generate the weights $\varpi_{k}=\frac{t_{k}}{n}$ for the domains. Where $t_{k}$ is the total score for domain $k$ and $n$ is the number of participants. In this regard, the weights reflect the basin's residents, stakeholders and experts knowledge and are based on consensus of people living and working in the basin. Sensitivity and adaptive capacity domains were ranked together to understand their relative importance. The results of the ranking are presented in results section. An overall exponentially transformed sensitivity and adaptive capacity scores are then derived using equations 9 and 10 respectively:

$$
\begin{aligned}
& S=-23 * \log \left\{1-R\left(\frac{1}{n_{l}} \sum_{l=1}^{l} d_{i} w_{k}\right) *\left[1-e^{-\lambda / 23}\right]\right\} \\
& A D=-23 * \log \left\{1-R\left(\frac{1}{n_{h}} \sum_{h=1}^{h} d_{j} w_{k}\right) *\left[1-e^{-\lambda / 23}\right]\right\}
\end{aligned}
$$

Where $\frac{1}{n_{l}} \sum_{l=1}^{l} d_{i} w_{k}$ and $\frac{1}{n_{h}} \sum_{h=1}^{h} d_{j} w_{k}$ are the sensitivity and adaptive capacity scores averaged over the respective number of domains $-n_{l}$ and $n_{h}$ are the number of sensitivity and adaptive capacity domains, respectively,

Having derived indices of sensitivity and adaptive capacity, the next stage of the analysis is to derive an overall index of vulnerability. Following the IPCC's conceptualizations of vulnerability (IPCC 2001) we assumed an inverse relationship between sensitivity and adaptive capacity in deriving an index of overall vulnerability. Equation 14 is then used to derive an exponentially transformed index of socioeconomic vulnerability $(V)$.
$V=-23 * \log \left\{1-R\left(\frac{S}{A D}\right) *\left[1-e^{-\lambda / 23}\right]\right\}$

Where $S$ and $A D$ are the Sensitivity and Adaptive capacity scores generated from equations 12 and 13 .

\subsection{Results}

\section{Key Environmental Issues Identified}

The key environmental issues identified in the basin were river bank erosion, flooding and droughts. The basin's residents reported that bank erosion is a continuous phenomenon. River bank erosion results in loss of livelihood mainly agricultural produce, contamination of drinking water, outbreak of diseases, loss of infrastructure (mainly housing, hospital, roads and bridges among others) and loss of ecosystems. River bank erosion and its impacts were clear during field observations. The residents reported that flooding is an annual occurrence, while droughts are more erratic. They vary temporally and spatially. Prolonged dry spells in the basin as a results of deficits in the monsoon confronts families with unprecedented hardships.

\section{Domains Identified and their Ranking}

Fourteen domains of sensitivity and adaptive capacity were identified and ranked using the Delphi technique. Fig. (8) shows the domains, their classification and ranking in order of importance or impact significance. Ten domains were classified as sensitivity domains and four as adaptive capacity domains. The rankings in Fig. (8) clearly shows that loss of livelihoods (including loss of agricultural land), destruction and loss of housing, ecosystem loss were the three major concerns raised. With regards to adaptive capacity, availability of economic alternatives and economic capacity were ranked the most important. Gender effects (impact on women), immigration and social networks although mentioned were not ranked high.

Excerpts of observations and discussion with the basin's residents, stakeholders and experts are presented in Table 4.

\section{Spatial Patterns in the Multi-Dimensions of Vulnerability}

Although fourteen domains of sensitivity and adaptive capacity were identified only six - livelihood, access to health services, road infrastructure, gender, economic alternatives and human capital are analysed and mapped in this study due to data limitation (Fig. 9). Nonetheless, with the availability of more data this analysis can be extended to cover more domains. The indicators used to profile the domains are shown in Table 5. The indicators selected to represent each domain were what the basin's residents, stakeholders and experts deemed appropriate to quantify the domain. The indicators were selected through discussions with local residents, stakeholders and experts. One-on-one discussions were also conducted with selected experts to affirm the reliability of the indicators selected.

Fig. (10) shows that level of sensitivity and adaptive capacity by domains. The scores have been categorised into quintiles (the least sensitive/adaptive $20 \%$ of communities to the most sensitive/adaptive $20 \%$ of communities). The blue course shows that Brahmaputra River. Fig. (10) depicts clear differentials in the level of sensitivity and adaptive capacity 


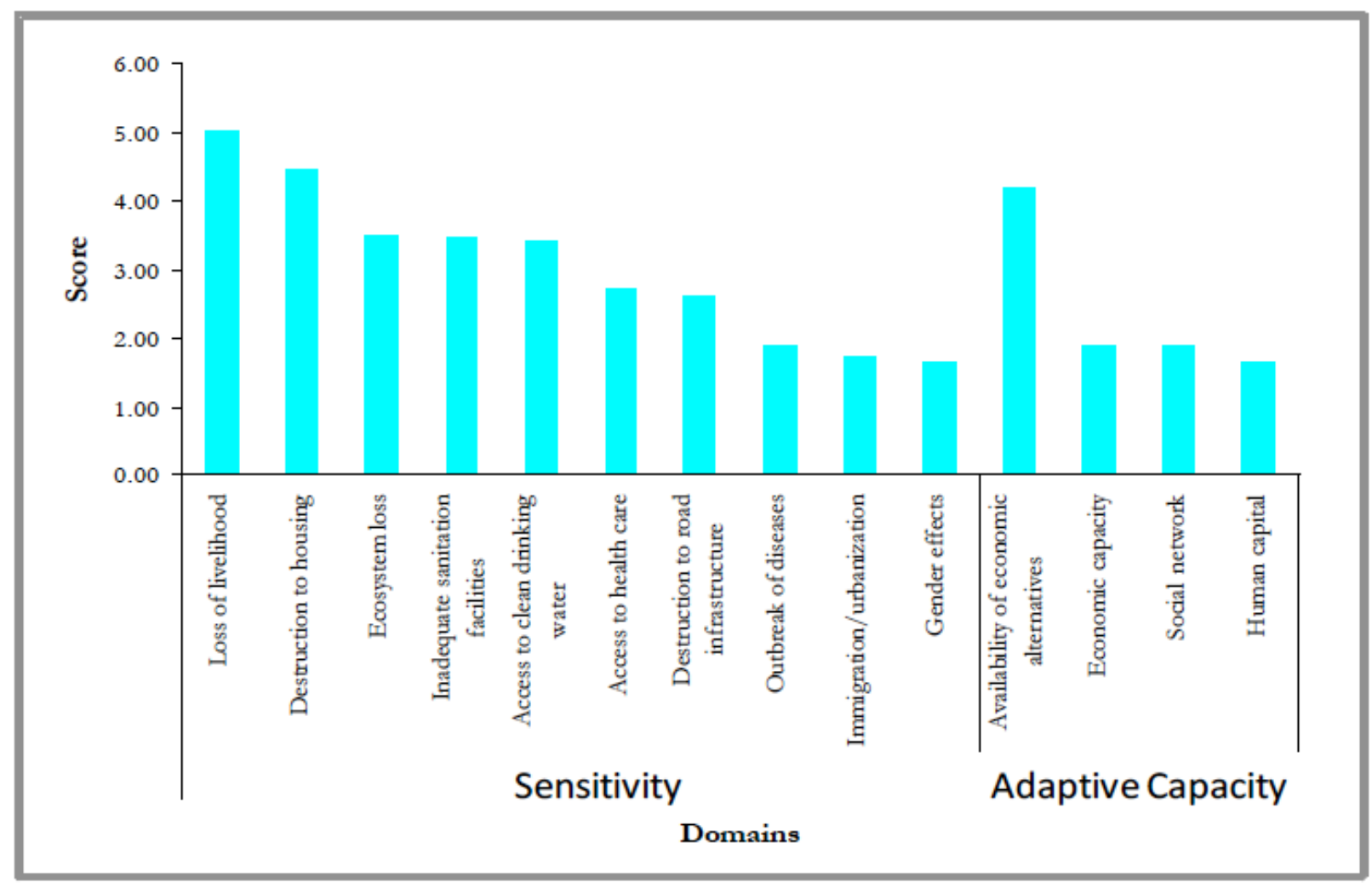

Fig. (8). Domains and their relative rankings.

Table 4. Excerpts from Observations and Discussion with the Basin's Residents, Stakeholders and Experts

\begin{tabular}{|c|c|c|}
\hline Domain & Problem & Who is Impacted \\
\hline Loss of livelihood & $\begin{array}{l}\text { Loss of farm produce, equipments and land leads to } \\
\text { loss of income through bank erosion }\end{array}$ & Communities with more engagement in agriculture \\
\hline Gender & $\begin{array}{l}\text { Women have more responsibility for providing } \\
\text { household resources that are climate sensitive, }\end{array}$ & Communities with marked gender disparities \\
\hline Availability of economic alternative & $\begin{array}{l}\text { The availability of alternatives income and liveli- } \\
\text { hood sources is vital for mitigating the effects of } \\
\text { livelihood loss through river bank erosion }\end{array}$ & $\begin{array}{l}\text { Communities with close proximity to cities most often } \\
\text { have better alternative economic opportunities }\end{array}$ \\
\hline Economic capacity & $\begin{array}{l}\text { Economic capacity of individuals, households and } \\
\text { communities are a key determinant of the ability to } \\
\text { cope or adjust to the impacts of environmental } \\
\text { disasters }\end{array}$ & $\begin{array}{l}\text { Communities less reliant on climate sensitive income } \\
\text { and livelihood activities }\end{array}$ \\
\hline Human resource capacity & $\begin{array}{l}\text { The ability to cope with bank erosion requires } \\
\text { knowledge about options, the capacity to assess } \\
\text { opportunities and the ability and skills to implement } \\
\text { the most suitable and sustainable options }\end{array}$ & $\begin{array}{l}\text { They noted that communities with high human capital } \\
\text { have greater adaptive capacity }\end{array}$ \\
\hline Immigration/urbanization & $\begin{array}{l}\text { The influx of migrants put pressure on already } \\
\text { limited resources leading to conflicts. Although } \\
\text { countered by economic input. Movement to cities } \\
\text { for work after loss of land }\end{array}$ & $\begin{array}{l}\text { Communities severely impacted such that migration is } \\
\text { required }\end{array}$ \\
\hline
\end{tabular}


Table 4. contd....

\begin{tabular}{|l|l|l|}
\hline \multicolumn{1}{|c|}{ Domain } & \multicolumn{1}{|c|}{ Problem } & \multicolumn{1}{c|}{ Who is Impacted } \\
\hline \hline Destruction to housing & Loss of housing and instigation of migration & Communities on river bank \\
\hline Ecosystem loss & $\begin{array}{l}\text { affects the composition and distribution of ecosys- } \\
\text { tems in the basin - access to food, medicine and } \\
\text { water }\end{array}$ & $\begin{array}{l}\text { Communities on river bank utilising river rslted eco- } \\
\text { logical resources }\end{array}$ \\
\hline Inadequate Sanitation facilities & Field observation: loss of resources for sanitation & Communities on river bank \\
\hline Source of drinking & Field observation: loss of resources for sanitation & Communities on river bank \\
\hline Health care & $\begin{array}{l}\text { Both direct and indirect physical and psychological } \\
\text { impacts of land and property loss }\end{array}$ & $\begin{array}{l}\text { Communities with inadequate health care facilities } \\
\text { and exposed to communicable diseases }\end{array}$ \\
\hline Road infrastructure & Loss of infra-structure & Communities reliant on trade and access \\
\hline
\end{tabular}

Table 5. Domains and Indicators Used at the Village/Town Level

\begin{tabular}{|c|c|}
\hline Domains & Indicators \\
\hline \multicolumn{2}{|l|}{ Sensitivity domains } \\
\hline Livelihood & $\begin{array}{l}\text { 1. Proportion of workers engaged in agriculture } \\
\text { 2. Main to marginal agricultural workers (The ratio of agricultural worker who work for more than } 6 \text { months } \\
\text { to those who work less than } 6 \text { months) } \\
\text { 3. Subsistence crop land (in } \mathrm{km}^{2} \text { ) per } 100 \text { households } \\
\text { 4. Commercial crop land (in } \mathrm{km}^{2} \text { ) per } 100 \text { household }\end{array}$ \\
\hline Access to health care & $\begin{array}{l}\text { 1. Distance to nearest allopathic hospitals } \\
\text { 2. Distance to nearest maternity and child welfare centres } \\
\text { 3. Distance to nearest public health centres }\end{array}$ \\
\hline Road infrastructure & $\begin{array}{l}\text { 1. Proportion of roads that are metalled } \\
\text { 2. Proportion of roads that are national roads } \\
\text { 3. Proportion of roads that are track paths } \\
\text { 4. Proportion of roads that are unmetalled roads } \\
\text { 5. Proportion of roads that are cart tracts } \\
\text { 6. Proportion of roads that are foot paths }\end{array}$ \\
\hline Gender & $\begin{array}{l}\text { 1. Female literacy rate } \\
\text { 2. Proportion of female workers engaged in non-agricultural work } \\
\text { 3. Sex ratio }\end{array}$ \\
\hline Adaptive capacity domain & \\
\hline Economic alternatives & $\begin{array}{l}\text { 1. Proportion of non-agricultural workers } \\
\text { 2. Distance to the nearest city or town }\end{array}$ \\
\hline Human Capital & $\begin{array}{l}\text { 1. Adult literacy rate } \\
\text { 2. Proportion of the population (7+ years) who are working } \\
\text { 3. Ratio of workers to non-workers (dependency ratio) } \\
\text { 4. Ratio of main workers to marginal workers }\end{array}$ \\
\hline
\end{tabular}



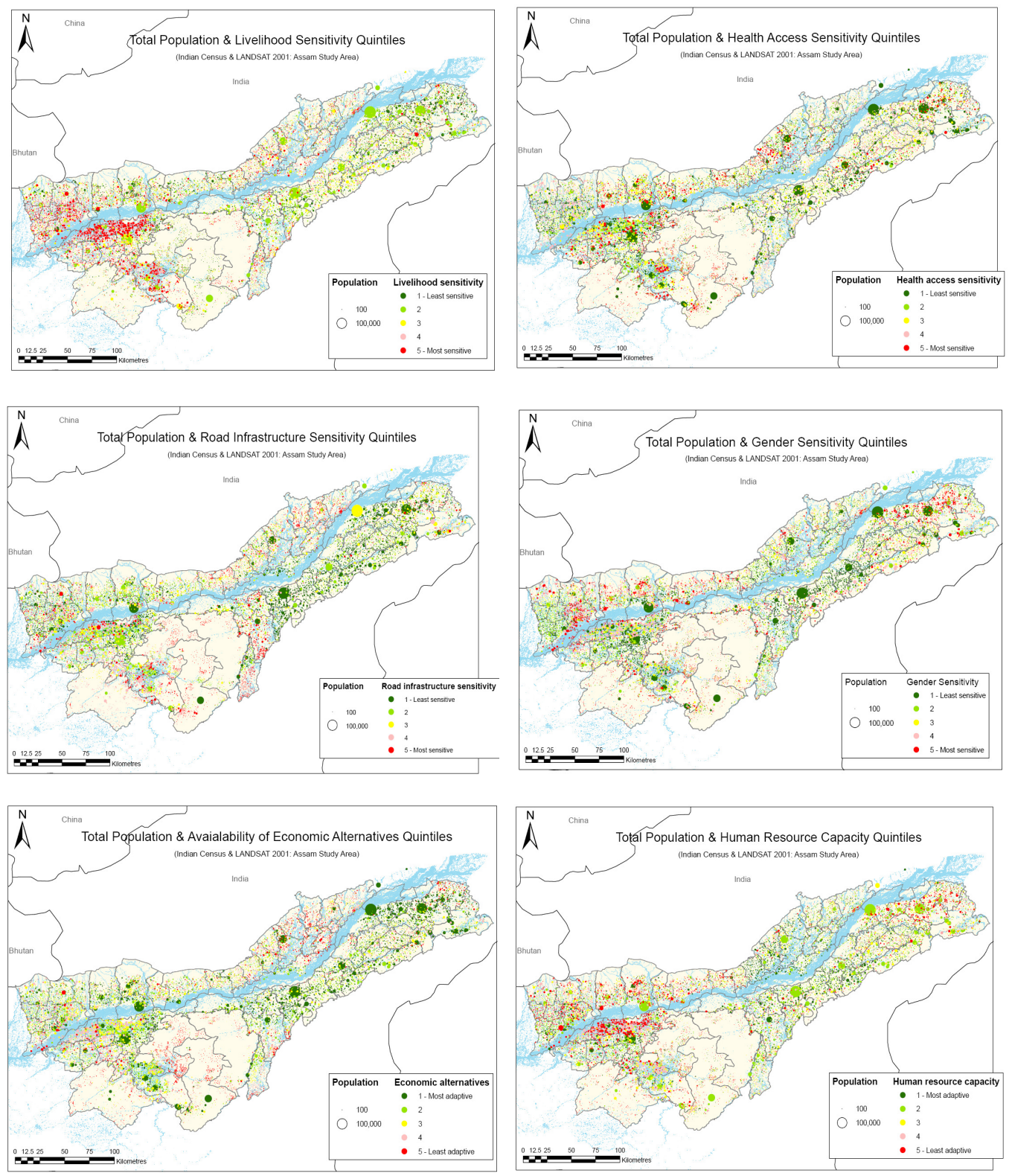

Fig. (9). Geographical variation in sensitivity and adaptive capacity by domain.

depending. These differentials are often masked when only one vulnerability score is created without considering its multi-dimensionality. Generally, Fig. (10) shows that small communities (with regards to population sizes) are the most sensitive communities and with the least adaptive capacity. There is also a concentration of sensitive and less adaptive communities in the western part of the basin. Considering livelihood sensitivity, Fig. (10) shows a cluster of sensitive communities in the western part of the basin. With regards to health, road infrastructure and gender sensitivity, sensitive communities are more spread-out but still with substantial clustering to the western part of the basin.

Considering spatial patterns in adaptive capacity, Fig. (10) shows that there is a high concentration of communities with fewer opportunities to alternative economic activities within the southwestern part of the basin and also in the Subansiri (I and II), Dhemaji, Kadam and Dibrugarh West Tehsils all to the north of the basin. There is also a high con- centration of communities with low human resource capacity within the western part of the basin and the Doom Dooma and Mergherita Tehsils.

\section{Spatial Patterns in the Level of Sensitivity and Adaptive Capacity}

Considering the overall level of sensitivity and adaptive capacity, Fig. (10) clearly reveals that in the main the most sensitivity communities are more likely to be the least adaptive communities which is perhaps understandable. A further analysis revealed a significant correlation of $-0.20(\mathrm{p}<0.001)$ between the sensitivity and adaptive capacity scores. Fig. (10) also reveals that the most sensitive and least adaptive communities are mainly within the western part of the basin and also along the river to the north. It can also be noted from Fig. (10) that there is a high concentration of communities with low sensitivity and high adaptive capacity within the northeast and south-eastern parts of the basin. 


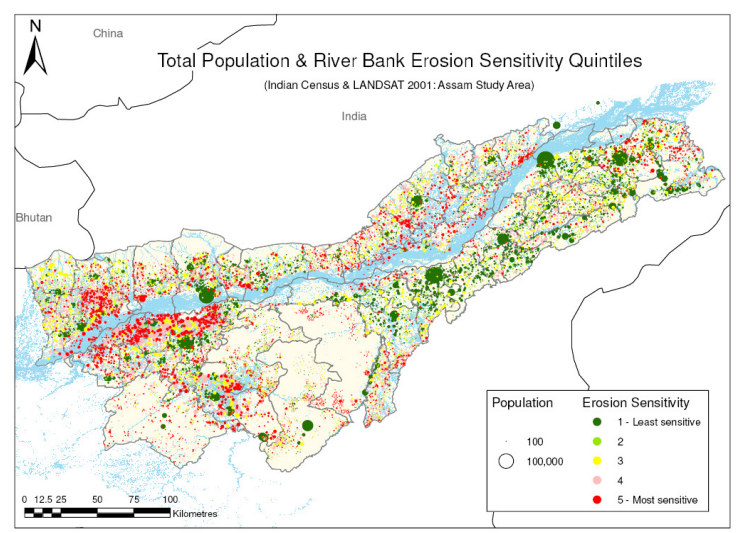

Fig. (10). Sensitivity and Adaptive Capacity.

\subsection{Spatial Patterns in Vulnerability}

It should be noted that the central criteria of the work was the development of the statistical methodology laid out above. There have been initial strategic assessments to validate the outcomes against local experience and a more thorough and detailed approach to this work approach is the subject of ongoing research strategies.

Fig. (11) shows the overall vulnerability map. The figure clearly shows that the most vulnerable communities are within the western, north-western and south-western part of the basin and along the river bank to the north. It is also clear from Fig. (11) that small communities are more vulnerable compared to main settlements. There is a high concentration of least vulnerable communities within the northeast and southeast of the basin, where communities are not located along the banks of the river. However, to the opposite where communities are located along the banks, it can be seen from

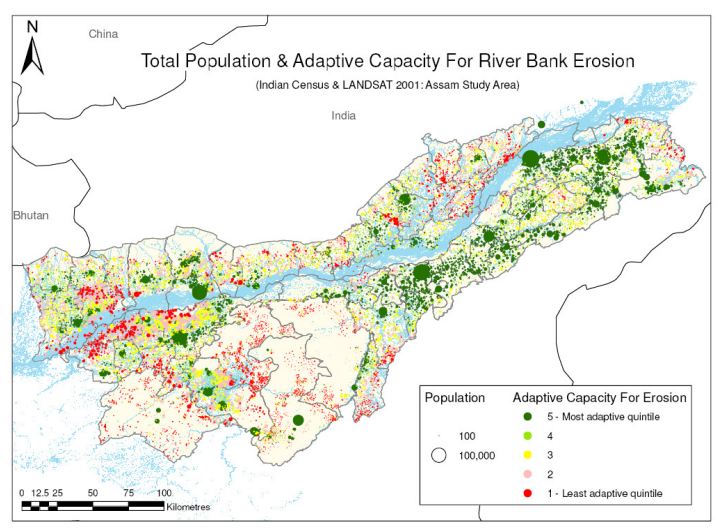

Fig. (11) that there is a high concentration of vulnerable communities.

Discussions with local experts associated with the Delphi process designed to weight the domains, provide a first order appreciation of the key elements of the spatial distribution of vulnerability in Fig. (11). Firstly the predomination of high vulnerability associated directly with the river and wetlands (southwest and northwest) can be, at least in the main, attributed to the substantive influx of the Bangladeshi community who by virtue of their migratory status have a tendency to have much lower access to health case and education as well as being economically utilised to carry out the least well paid jobs in the region. Whilst it would be desirable to clearly identify this through the census there is a pressure upon the immigrant population to identify themselves as of Indian origin and as such this data is therefore seemed unreliable. There is a clear region of low vulnerability to bank erosion in the southeast of the map which is thought to reflect the

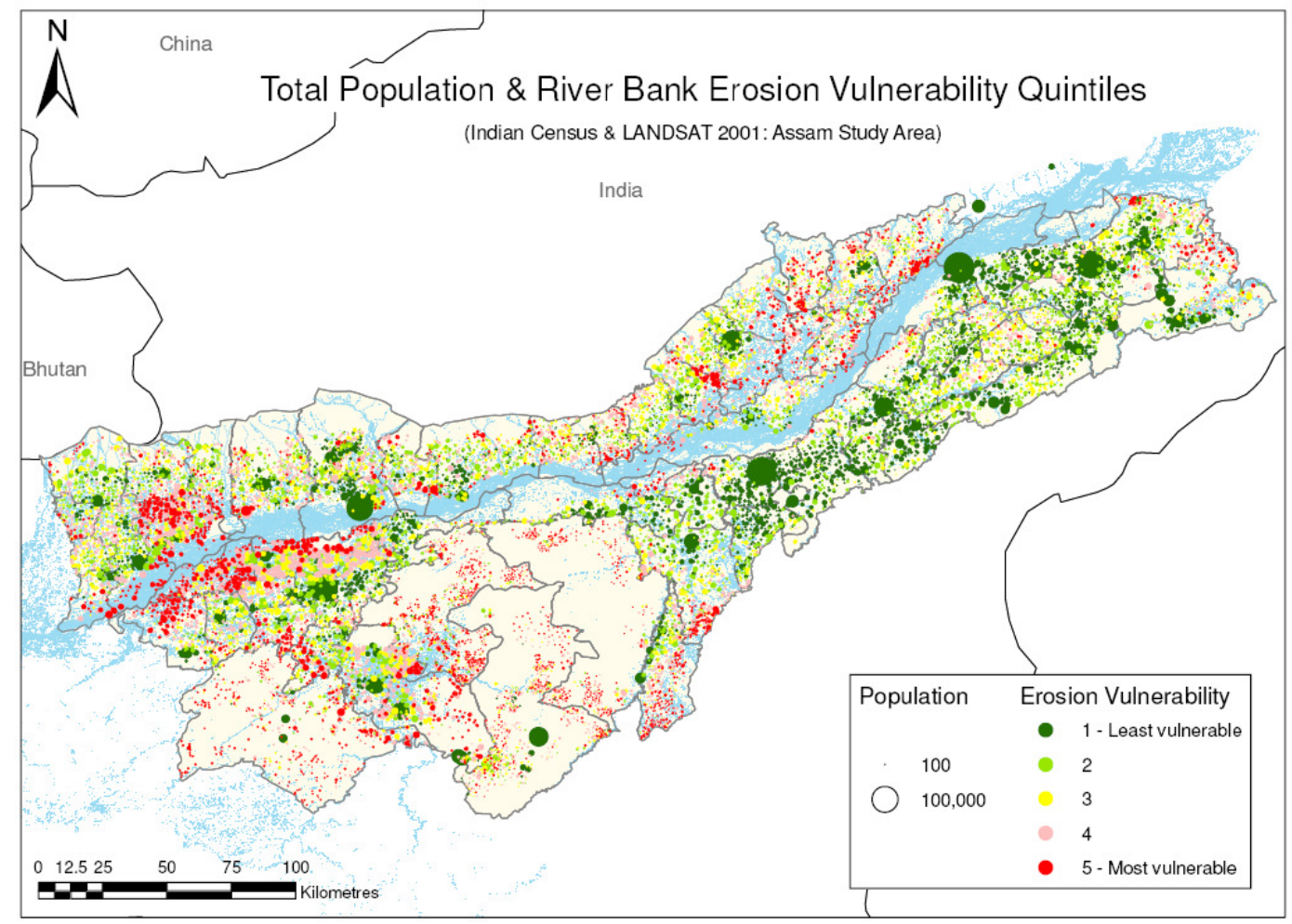

Fig. (11). Vulnerability map. 
higher status afforded to the workers of commercial plantations in terms of access to education and health care as well as greater communication, substantive river defence networks and ties to the socio-economically low vulnerability urban areas.

\section{SUMMARY AND RESEARCH RECOMMENDA- TIONS}

The work here presents the case for multidisciplinary approaches to the characterisation of Risk, Vulnerability and Hazard. By giving a spatial dimension to both the physical and the social components it is then possible to define Risk within the context of a map. This approach is however limited at present to a simple coincident overlay of the identified vulnerability and hazard areas and no account is taken of the potentially complexities that underpin such a process as the impact of bank erosion upon communities. However, the authors would suggest that in terms of the decision making processes undertaken by relevant authorities and policy making bodies such an approach remain relevant and effective.

Below are some key points for discussion related to this approach:

- The fluvial hydrodynamics have been profoundly influencing the channel self adjustment processes of the Brahmaputra causing mostly channel aggradations and attendant fluvial landform changes, channel migration, widening or channel abandonment, avulsion phenomena varied at spatial and temporal scale. One of the notable outcomes of the present investigation is a pointer to the intimate relationship between land losses due to bank erosion with corresponding increase in braiding intensity. Braiding intensity is exacerbated by high energy environment of flow domain with heavy sediment inputs from the associated catchments.

- The present research has demonstrated the rational use of the newer braiding indicator namely Plan Form Index (PFI) developed by Sharma [10] with high resolution remote sensing satellite data application to analyze and monitor the complex braiding behaviour of a large braided river like the Brahmaputra. The present study also shows that Plan Form Index (PFI) suitably fulfills the need for a rational braiding indicator which should be easy to compute making use of synoptic coverage provided by satellite imageries. However, adopting the thresholds developed by Sharma [10] for the Brahmaputra PFI can also be used to identify unbraided river reach.

- The methods outlined above identifies that river bank erosion is one of the main environmental concerns in the basin alongside floods and droughts. River bank erosion is a continuous process with adverse environmental and socioeconomic consequences - loss of livelihood (mainly agricultural produce and land), loss of essential infrastructure (housing, health centres, roads, bridges, etc.), contamination of drinking water, and loss of ecosystems.

- Vulnerability is placed within a context of risk within this study. However it is important to recognise that there are substantial subjective elements to the devel- opment of the conceptual framework as well as in the gathering and presentation of qualitative data. However, once a framework is accepted it offers a structure approach to interpretation and assessment of information relating to the social vulnerability of the rural population. A key area of research in this field should be the validation of such an approach over time. This is clearly difficult as the challenge is to validate a perception based model, however progress might be made on assessing impacts on hazards on regions where vulnerability assessments have been made.

- In the vulnerability modelling Loss of livelihoods (including loss of agricultural land), Destruction and loss of housing and Ecosystem loss were the three major concerns raised. The availability of economic alternatives and the economic capacity of residents were mentioned to be the potential adaptive measures. Impacts on women, immigration and social networks are mentioned but not ranked highly which may be reflective of the social attitudes inherent in the decision makers. Indeed there was a preponderance of engineering based disciplines within the workshop and on occasions issues of gender were dismissed as irrelevant. The argument of the relevance of gender and other social contexts are a substantial study in themselves and sit outside of the realm of this study, however they do offer a guidance for further research and possibly capacity building in this field.

- The results show that generally, small communities (with regards to population sizes) are the most sensitive communities and with the least adaptive capacity. Overall, the results also show that the most sensitive and least adaptive communities are located mainly within the western part of the basin and also along the river to the north and this has a strong (although by no means exclusive) coincidence with the immigrant population. Further investigation as to the relationship between the above trend revealed on the map and the relationship with the cultural and social context would be a valuable research program for the future.

- Early on in a decision making process related to the implementation of a vulnerability mapping approach it becomes necessary to make a choice as to whether the vulnerability being discussed is that of the population of communities in the rural areas vulnerability from the perspective of infra-structure and asset (as is often the case in Europe). The significance of this choice is that it can result in diametrically opposite maps with the poorest of the poor often being least associated with infra-structure of value (at least in a rural setting). In this work we define vulnerability in the context of community level poverty and deprivation as opposed to through the exposure of asset.

\section{REFERENCES}

[1] Goswami DC. Brahmaputra River, Assam, India: Physiography, basin denudation and channel aggradation. Water Res 1985; 21 959-78.

[2] Office of the Registrar General \& Census Commissioner. 2001 India Population and Housing Census. India 2001.

[3] Sharma N, Sankhua RN, Pandey AD. Spatio-temporal modelling of hydrological variability for the river Brahmaputra using artificial 
neural network. Role of water sciences in transboundary river basin management, Thailand 2005.

[4] Pahuja S, Goswami DC. A fluvial geomorphology perspective on the knowledge base of the Brahmaputra. Paper commissioned as an input to the study on Development and Growth in Northeast India: The Natural Resources, Water, and Environment Nexus, India 2006.

[5] Chaudhari SN, Sinha S. Flood management in Assam - a viewpoint. JIWWA 1999; 31: 138-40.

[6] Reuveny R. Climate change-induced migration and violent conflict. Polit Geogr 2007; 26: 656-73.

[7] PDD. Assam Development Report. Planning \& Development Department, Government of Assam, Guwahati 2003.

[8] IPCC. Climate Change 2001: Impacts, Adaptation and Vulnerability. Contribution to the working group I to the third assessment report of the Intergovernmental Panel on Climate Change. Cambridge: Cambridge University Press, 2001.

[9] Sarma JN. Fluvial process and morphology of the Brahmaputra River in Assam, India. Geomorphology 2005; 70: 226-56.

[10] Sharma N. Mathematical modelling and braid indicators - the Brahmaputra Basin water resources. Dordrecht, Kluwer Academic Publishers 2004; vol. 47: pp. 229-60.
[11] Villagrán JCV. Vulnerability: a conceptual and methodological review. UNU Institute for Environment and Human Security (UNU-EHS): Bonn 2006.

[12] Birkmann J, Ed. Measuring vulnerability to natural hazards - towards disaster resilient societies. Tokyo, United Nations University 2006.

[13] Thomalla F, Downing T, Spanger-Siegfried E, Han G, Rockström J. Reducing hazard vulnerability: towards a common approach between disaster risk reduction and climate adaptation. Disasters 2006; 30: 39-48.

[14] IPCC. Climate Change 2001: Synthesis report. World Meteorological Organization. UN Environment Programme: Geneva 2001.

[15] White P, Pelling M, Sen K, Seddon D, Russell S, Few R. Disaster Risk Reduction: a development concern. DFID United Kingdom 2005.

[16] Villagrán JCV. La naturaleza de los Riesgos Asociados a Varias Amenazas en Poblados de Guatemala. Technical report prepared for SEGEPLAN, Guatemala 2001

[17] Jones B, Andrey J. Vulnerability index construction: methodological choices and their influence on identifying vulnerable neighborhoods. Int J Emerg Med 2007; 4: 269-95.

[18] The Scottish Government. Scottish index of multiple deprivation. A Scottish Executive National Statistics Publication: Edinburgh 2006.

(c) Sharma et al.; Licensee Bentham Open.

This is an open access article licensed under the terms of the Creative Commons Attribution Non-Commercial License (http://creativecommons.org/licenses/by-nc/3.0/) which permits unrestricted, non-commercial use, distribution and reproduction in any medium, provided the work is properly cited. 